\title{
Are copepods secondary hosts of Cycliophora?
}

\author{
Ricardo Cardoso Neves • Xavier Bailly • \\ Heinrich Reichert
}

Received: 28 April 2014 / Accepted: 16 June 2014 /Published online: 1 July 2014

(C) Gesellschaft für Biologische Systematik 2014

\begin{abstract}
Ever since the first observations in the late 1960s, Cycliophora were found exclusively living epizoically on lobsters belonging to the family Nephropidae. The complex cycliophoran life cycle, with alternation of asexual and sexual generations, takes place only in the microhabitat provided by the host mouthparts. Herein, we report the first evidence of a symbiotic relationship between cycliophorans and organisms other than nephropid lobsters, namely, the harpacticoid copepods. Two specimens of copepods associated with cycliophoran life cycle stages were collected from the segmental mouthparts of a European lobster, Homarus gammarus. One of the copepods carried two feeding stages with long stalks, which probably belong to an undescribed Symbion sp., while the other copepod was found bearing an undetermined settled stage. We discuss the implications of these novel observations for the understanding of the Cycliophora life cycle and their dispersion abilities.
\end{abstract}

Keywords Symbion sp · Evolution of life cycle $\cdot$ Homarus gammarus $\cdot$ Population dispersion $\cdot$ Spiralia $\cdot$ Lophotrochozoa

\section{Introduction}

Cycliophora is a phylum of microscopic animals known since the 1960s but described only as late as in 1995 (Funch and Kristensen 1995, 1997). The first-described species, Symbion pandora, Funch and Kristensen 1995 is a commensal

R. C. Neves $(\bowtie) \cdot H$. Reichert

Biozentrum, University of Basel, Klingelbergstrasse 50, 4056 Basel,

Switzerland

e-mail: ricardon.6@gmail.com

X. Bailly

CNRS-UPMC, UMR 7144, Station Biologique de Roscoff, Place

Georges Teissier, 29682 Roscoff Cedex, France organism that lives attached to the mouth parts of the Norway lobsters, Nephrops norvegicus Linneus, 1758. In addition, two other cycliophoran species are known: Symbion americanus Obst, Funch and Kristensen, 2006, lives on the American lobster, Homarus americanus H. Milne-Edwards, 1837 (Obst et al. 2006), and a third undescribed cycliophoran species is a epizoit on the European lobster, Homarus gammarus Linnaeus, 1758 (cf. Funch and Kristensen 1997). Evidence from the molecular characterization of cycliophorans suggested, however, the existence of cryptic species in S. americanus (Obst et al. 2005; Baker and Giribet 2007; Baker et al. 2007). Cycliophorans are highly host specific, and their complete life cycle takes place on the sheltered microhabitat provided by the mouthparts of the lobster host (Obst and Funch 2005).

The cycliophoran life cycle involves various sexual and asexual stages that alternate in a complex succession of events (Funch and Kristensen 1999; Obst and Funch 2003). The most prominent stage is a polyp-like, sessile individual with a body divided into an anterior buccal funnel, an oval trunk and a posterior stalk ending as an attachment disk. This is the only cycliophoran stage able to feed and is characterized internally by a U-shaped gut. Living permanently attached to the lobster's mouth parts, the feeding stage spends its whole life filtering food particles suspended in the water with the help of cilia surrounding the mouth aperture (Riisgård et al. 2000). The buccal funnel and gut are recurrently replaced in a regenerative process that implicates the appearance of wrinkles in the cuticle of the trunk (Funch and Kristensen 1995). Moreover, a single feeding individual is able to generate free swimming stages, one at a time, by an internal budding process that occurs in a brooding chamber located in the trunk (Funch and Kristensen 1997).

The Pandora larva is a free swimming larval stage generated asexually inside the feeding stage. Once released, the Pandora larva settles close to the maternal feeding individual 
and develops into a new feeding stage. Asexual reproduction in cycliophorans appears to contribute to a fast growth of the population in a single host (Funch and Kristensen 1997). The sexual part of the life cycle involves initially a Prometheus larva and a female, which are also generated by inner budding inside the feeding stage. Once freed, the Prometheus larva settles on the trunk of a feeding individual and generates dwarf males inside its body (Obst and Funch 2003; Neves et al. 2010). The female is impregnated by the dwarf male and the embryo develops into a chordoid larva (Funch 1996; Neves et al. 2012). The chordoid larva settles on a new host individual and eventually develops into a new feeding stage, thus closing the sexual part of the life cycle. Therefore, the chordoid larva is regarded as the cycliophoran dispersal stage.

Herein, we report the first evidence of symbiotic relationships of cycliophorans with copepods, an abundant group that includes parasites of a wide range of hosts and microhabitats (Boxshall 2005). These insights provide new information about the cycliophoran life cycle, one of the most complex known within Metazoa as well as in their dispersion strategies. Furthermore, we discuss possible advantages and disadvantages of this symbiotic relationship between cycliophorans and copepods.

\section{Material and methods}

Specimens of the European lobster, H. gammarus, were collected by a local fisherman in Brittany (France), off the coast of Roscoff in February 2012. Mouthparts from one of the lobsters with numerous specimens of Symbion sp. attached were dissected from the host and placed in Petri dishes with filtered seawater. An inspection of the Petri dish under the stereomicroscope revealed the presence of a copepod swimming freely with two cycliophoran specimens sitting on its cuticular exoskeleton. The copepod specimen, together with the attached cycliophorans, was fixed for $1 \mathrm{~h}$ in $4 \%$ paraformaldehyde (PFA) at room temperature. Afterwards, the specimens were washed $3 \times 15 \mathrm{~min}$ in PBS containing $0.1 \%$ sodium azide $\left(\mathrm{NaN}_{3}\right)$ and subsequently stored at $4{ }^{\circ} \mathrm{C}$.

The Petri dish with the mouthparts was kept inside a refrigerator at approximately $10{ }^{\circ} \mathrm{C}$ and the water changed daily. In the following days, the Petri dish was checked thrice a day, and approximately $48 \mathrm{~h}$ after the dissection of the host's mouth parts, a second copepod carrying a cycliophoran stage was found. The specimens were fixed and preserved as described above.

Specimens were first studied with an Olympus SZX 12 stereomicroscope. Afterwards, specimens were mounted in Fluoromount $\mathrm{G}$ (Southern Biotech) on glass slides and studied with a Leica DM6000 B light microscope with phase contrast and DIC optics using magnifications between $\times 10$ and $\times 40$. The first copepod was embedded with the two feeding stages attached to its body; however, the second copepod was mounted separate to the cycliophoran stage initially found attached to its body. This is because during the preliminary investigation under the stereomicroscope, the cycliophoran stage detached from the cuticle of the copepod host.

\section{Results}

The mouth parts of the lobster investigated during this study were colonized with a high-density cycliophoran population (i.e., $>50$ individuals per mouth part). The two copepods found associated with cycliophorans are characterized by a podoplean body plan, tapering posteriorly, in which the major body articulation is located between the fourth and fifth pedigerous (leg-bearing) somites (Fig. 1). The external morphology of the copepods is anatomically in accordance with that of the order Harpacticoida and, apparently, family Miraciidae (see Huys et al. 1996; Wells 2007). Anteriorly, the somite bearing the first pair of swimming legs is fused to the cephalosome, thus forming a cephalothorax. Posteriorly to this, three free prosomites bear the second to fourth pairs of swimming legs. In the posterior region of the body, the urosome is composed of an anterior somite bearing the fifth pair of legs and four other somites. The second urosomite is the longest in the urosome, which suggests that it may result from the fusion of two urosomites - the so-called doublesomite - as typically observed in harpacticoid females. The anal urosomite bears two posterior caudal rami. In addition, the antennules have nine segments. Nevertheless, the identification of the species remains elusive because important morphological features, e.g. in the antennae and mandible, were not possible to study in the two non-dissected specimens.

The copepod specimen carrying two cycliophorans was found immediately after the dissection of the lobster's mouthparts (Fig. 1a). The cycliophoran specimens are two feeding stages attached to the copepod: one individual is sitting on the prosome, at the level of the third free prosomite (leg-bearing segment), while the other is attached to the fourth segment of the host's urosome. The latter cycliophoran specimen is approximately $425 \mu \mathrm{m}$ in total length, i.e. from the buccal funnel to the attachment disk. Since both feeding stages possess a long stalk, these specimens probably belong to the undescribed Symbion sp. that is hosted exclusively by the European lobster, $H$. gammarus. A careful inspection inside the trunk of both feeding stages revealed neither a free swimming stage being generated in a brooding chamber nor a new buccal funnel preformed and ascending to replace the older feeding structure. However, at least three wrinkles are found in the cuticle of the trunk in one of the feeding individuals, which indicates intensive activity in the replacement of the feeding structure (see insert in Fig. 1a). 
Fig. 1 Cycliophoran life cycle stages attached to harpacticoid copepods; light micrographs. a Two Symbion sp. feeding stages $\left(f_{s_{1-2}}\right)$ attached, respectively, to the metasome and the urosome of a copepod host. The anterior region of the copepod (co) is facing left. The insert figure shows a close up of the trunk of one of the feeding stages with several wrinkles (arrowheads) on the cuticle. b Undetermined cycliophoran stage (ucs) settled on the urosome of a copepod host (co). The anterior of the copepod is facing right. c Same cycliophoran life cycle stage as shown in $\mathbf{b}$, but detached from the copepod host. Note the folded cuticle on its most posterior region. The insert figure shows a close up of the attachment disk that characterizes the most anterior region of this cycliophoran stage. an antennule, as anal somite, ce cephalothorax, $c r$ caudal rami, $d s$ double-somite, $e y$ eye, $p c$ posterior folded cuticle, sl swimming legs
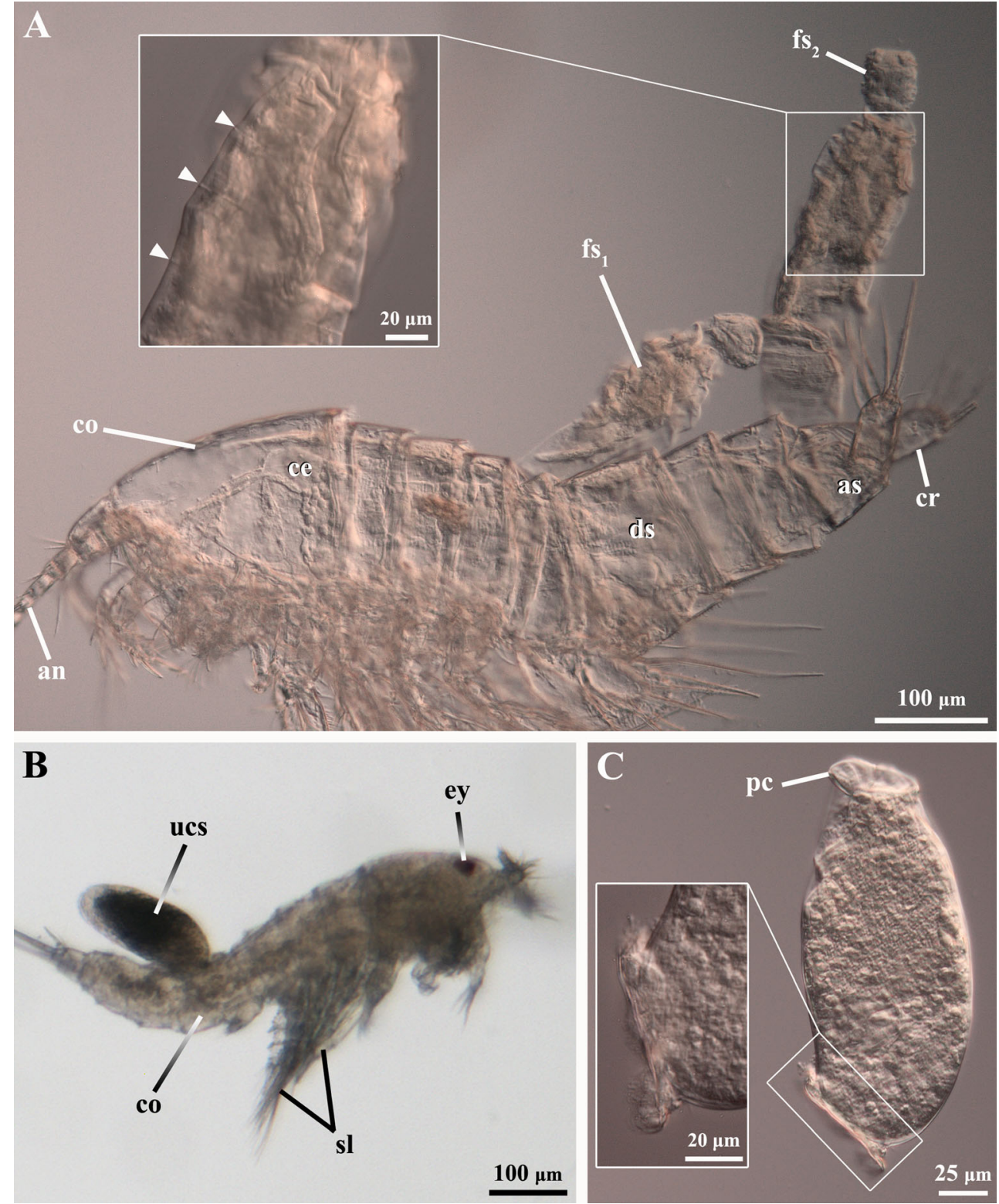

The cycliophoran specimen found sitting on the second copepod is attached to the urosome region, though very close to the metasome (Fig. 1b). The cycliophoran individual is a settled free swimming stage that is characterized by an attachment disk on its most anterior region and by a cuticular fold on the most posterior region (Fig. 1c). The total length from the posterior region to the attachment disk is of approximately $185 \mu \mathrm{m}$. A careful observation of the internal anatomy of the specimen did not reveal the presence of a buccal funnel or a large oocyte, which could help in identifying the specimen as a settled Pandora larva or female, respectively. In addition, structures that could be used to identify the specimen as a Prometheus larva were not found as well. Therefore, because the life cycle stages of Symbion sp. living on the European lobster are not formally described, the specimen is identified as undetermined settled stage.

\section{Discussion}

Hitherto, cycliophorans were characterized by a high degree of host specificity; only three lobster species within the family Nephropidae, namely, $N$. norvegicus, $H$. gammarus and $H$. americanus, were known to provide the adequate microhabitat for these small epizoans. In addition, a recent survey on museum specimens collected worldwide reported the absence of cycliophorans in several crustaceans other than these three species (Plaza 2012). During this survey, cycliophorans were not found in Nephropsis agassizi, which also belongs to the family Nephropidae or in several other crustaceans belonging to various families distributed in infraorders such as Achelata (e.g. Palinuridae), Anomura (e.g. Paguridae), Astacidea (e.g. Cambaridae), Axiidea (e.g. Callianassidae) and Brachyura (e.g. Potamidae). Therefore, the finding of a 
symbiotic relationship between Cycliophora and copepods raises several questions about the cycliophoran life cycle and their dispersion abilities.

In the Norway lobster, $N$. norvegicus, cycliophorans are found solely in specimens with carapace lengths of more than $35 \mathrm{~mm}$ (Obst and Funch 2005). This is probably related to the moulting activity of the host; young lobsters are characterized by intermoulting periods of short duration, while old lobsters moult less frequently (Castro 1992). Therefore, longer intermoulting periods of the host allow cycliophorans to reproduce and establish a sexual, high-density population in the lobster's mouthparts. The copepods investigated during this study possess a small body that could never accommodate a high-density population of Cycliophora. However, it is important to know more about the moulting activity of copepods carrying cycliophorans and to understand better the temporal relationship between these two symbionts. The several wrinkles found in the cuticle of one of the feeding stages investigated during this study indicate that the buccal funnel and gut apparatus were replaced several times. Since the cycliophoran feeding individual is a sessile stage, this means that the repeated buccal funnel replacements occurred after the colonization of the copepod as well as during a single intermoult period of the host. In addition, this indicates that the feeding individuals were well fed and could thus allocate energy to regenerative processes.

Cycliophoran feeding individuals tend to aggregate on the distal region of the lobster's mouth parts, which facilitates the access to food particles suspended in the water (Obst and Funch, 2006). Furthermore, cycliophorans are regarded as obligatory commensals because they feed only when the host starts its own feeding activity (Funch et al. 2008). Since the majority of Harpacticoida are sediment dwellers, it would be interesting to know more about the life history of the copepods carrying cycliophorans and to understand if they spend all their life time in the lobster's mouthparts or if, at a given moment, they move into another niche, e.g. the benthic sediments (Giere 2009). The consequence of this separation could actually be harmful to the cycliophoran feeding stages due to their dependency on the lobster host in order to feed. However, if the copepod spends its whole life time on the lobsters' mouth parts, it may actually be advantageous for the feeding stage to settle down on this small crustacean. Indeed, these feeding individuals would have first access to the food particles suspended in the water and gain some advantage in the competition with the other feeding individuals sitting directly on the lobster's mouth parts.

Not much is known concerning the selection of the substrate by the free swimming stages as they settle down on the host. However, they all have anterior sensory organs composed of relatively long cilia that probably play an important role in determining the most suitable settlement site (Funch and Kristensen 1997; Obst et al. 2006; Neves et al. 2012). The feeding stages investigated in this study result from the settlement of a Pandora larva or a chordoid larva. In both cases, the free swimming stage was able to settle not on the integument of a nephropid lobster but on that of a harpacticoid copepod. It thus seems that cycliophorans are not as highly host specific as thought before, which might have implications for the dispersal ability of this group. In the complex life cycle of Cycliophora, the chordoid larva was so far regarded as the dispersal stage because of their relatively fast swimming abilities (Funch and Kristensen 1995, 1997; Funch 1996). However, it is now known that cycliophoran feeding individuals may travel attached to a copepod. Whether these feeding individuals may act as dispersal stages by means of generating free swimming stages that could colonize a new lobster host is still unclear.

New attempts to find cycliophorans settled on copepods took place on May 2012, February 2013 and March 2014, in Roscoff. Two European lobsters were inspected on each trial, though the cycliophoran populations were small in all cases and the copepods found were not carrying cycliophorans. It is thus also possible that such symbiosis occurs only when the cycliophoran population is of high density. Indeed, in such conditions, copepods may simply represent an area that is available for the settlement of a cycliophoran larva. In the future, a thorough survey on the three nephropid lobsters known to host cycliophorans should be carried out in distinct geographical places. Furthermore, an inspection of copepods collected from the pelagic zone, especially in areas inhabited by nephropid lobsters, would be important to investigate further their role in the dispersion of cycliophorans. This would provide a comprehensive understanding about the role of copepods in the life cycle of Cycliophora and their population dispersion.

Acknowledgments We are grateful to the technical support by the staff from the Marine Station of Roscoff. Funding to support the collection in Roscoff was partially provided by EU programme ASSEMBLE - grant agreement no. 227799. Reinhardt Møbjerg Kristensen (Copenhagen) and Peter Funch (Aarhus) are acknowledged for many discussions on the subject.

\section{References}

Baker, J. M., \& Giribet, G. (2007). A molecular phylogenetic approach to the phylum Cycliophora provides further evidence for cryptic speciation in Symbion americanus. Zoologica Scripta, 36, 353-359.

Baker, J. M., Funch, P., \& Giribet, G. (2007). Cryptic speciation in the recently discovered American cycliophoran Symbion americanus; genetic structure and population expansion. Marine Biology, 151, 2183-2193.

Boxshall, G. A. (2005). Crustacean parasites: Copepoda (copepods). In K. Rohde (Ed.), Marine Parasitology (pp. 123-138). Melbourne: CSIRO Publishing.

Castro, M. (1992). A methodology for obtaining information on the age structure and growth rates of the Norway lobster, Nephrops 
norvegicus (L) (Decapoda, Nephropoidea). Crustaceana, 63, 2943.

Funch, P. (1996). The chordoid larva of Symbion pandora (Cycliophora) is a modified trochophore. Journal of Morphology, 230, 231-263.

Funch, P., \& Kristensen, R. M. (1995). Cycliophora is a new phylum with affinities to entoprocta and ectoprocta. Nature, 378, 711-714.

Funch, P., \& Kristensen, R. M. (1997). Cycliophora. In F. W. Harrison \& R. M. Woollacott (Eds.), Microscopic anatomy of invertebrates (Lophophorates, Entoprocta and Cycliophora) (Vol. 13, pp. 409474). New York: Wiley-Liss.

Funch, P., \& Kristensen, R. M. (1999). Cycliophora. In E. Knobil \& J. D. Neill (Eds.), Encyclopaedia of reproduction (Vol. 1, pp. 800-808). New York: Academic.

Funch, P., Thor, P., \& Obst, M. (2008). Symbiotic relations and feeding biology of Symbion pandora (Cycliophora) and Triticella flava (Bryozoa). Vie Milieu, 58, 185-188.

Giere, O. (2009). Meiobenthology, the microscopic motile fauna of aquatic sediments (2nd ed.). Berlin: Springer Verlag.

Huys, R., Gee, J. M., Moore, C. G., \& Hamond, R. (1996). Marine and brackish water harpacticoid copepods. Part 1. Keys and notes for identification of the species. In R. S. K. Barnes \& J. H. Crothers (Eds.), Synopses of the British fauna, new series 51. Field Studies Council: Shrewsbury.

Neves, R. C., Cunha, M. R., Funch, P., Wanninger, A., \& Kristensen, R. M. (2010). External morphology of the cycliophoran dwarf male: a comparative study of Symbion pandora and S. americanus. Helgoland Marine Research, 64, 257-262.

Neves, R. C., Kristensen, R. M., \& Funch, P. (2012). Ultrastructure and morphology of the cycliophoran female. Journal of Morphology, 273, 850-869.

Obst, M., \& Funch, P. (2003). Dwarf male of Symbion pandora (Cycliophora). Journal of Morphology, 255, 261-278.

Obst, M., \& Funch, P. (2005). The microhabitat of Symbion pandora (Cycliophora) on the mouthparts of its host Nephrops norvegicus (Decapoda: Nephropidae). Marine Biology, 148, 945-951.

Obst, M., Funch, P., \& Giribet, G. (2005). Hidden diversity and host specificity in cycliophorans: a phylogeographic analysis along the North Atlantic and Mediterranean Sea. Molecular Ecology, 14, 4427-4440.

Obst, M., Funch, P., \& Kristensen, R. M. (2006). A new species of Cycliophora from the mouthparts of the American lobster, Homarus americanus (Nephropidae, Decapoda). Organisms, Diversity and Evolution, 6, 83-97.

Plaza, M. (2012). Cycliophoran host range. Bulletin of the Peabody Museum of Natural History, 53, 389-395.

Riisgård, H. U., Nielsen, C., \& Larsen, P. S. (2000). Downstream collecting in ciliary suspension feeders: the catch-up principle. Marine Ecology Progress Series, 207, 33-51.

Wells, J. B. J. (2007). An annotated checklist and keys to the species of Copepoda Harpacticoida (Crustacea). Zootaxa, 1568, 1-872. 